\title{
Солнцева Елена Сергеевна
}

Санкт-Петербургский государственный университет,

Россия, 199034, Санкт-Петербург, Университетская наб., 11;

shelestelena@yandex.ru

\section{Виды связности в медиадискурсе}

Для цитирования: Солниева Е.С. Виды связности в медиадискурсе // Вестник Санкт-Петербургского университета. Язык и литература. 2018. Т.15. Вып. 3. С.481-491. https://doi. org/10.21638/spbu09.2018.312

В статье рассматриваются виды связности в медиадискурсе, анализируется, с чем и как связан современный медиатекст, прослеживаются характер и глубина этих связей, а также взаимовлияние таких свойств медиадискурса, как связность, гипертекстуальность и поликодовость. Материалом исследования послужили 100 немецко- и англоязычных публицистических текстов из электронных версий изданий «The New York Times» и «Frankfurter Allgemeine Zeitung», которые на сегодняшний день считаются одними из самых авторитетных и читаемых СМИ по всему миру. Кроме того, в связи с выборами в США в ноябре 2016 г. рассматривается то, как знаковое событие отразилось в текстах, с одной стороны, американских изданий, а с другой - европейских, неанглоязычных. Внимание уделяется прежде всего сходству двух изданий в изучаемом аспекте. Выделяются четыре основных вида связности в медиадискурсе: локальная, глобальная, поликодовая и гипертекстуальная. Локальная связность исследуемых текстов в медиадискурсе маркируется в языке на лексико-семантическом уровне, в частности в характере номинаций. В случае со знаковыми событиями цепочки одинаковых или схожих номинаций охватывают уже не только ряд статей, но также и целые издания и, выходя за рамки отдельных предложений или текстов, начинают формировать глобальную, тематическую связность в медиадискурсе. Кроме того, медиатексты обнаруживают связность экстралингвистического характера. Она проявляется в наличии релевантных ссылок на новостные сообщения, а также нерелевантных ссылок на рекламу и социальные сети, которые позволяют делиться новостью и обсуждать ее с другими участниками веб-пространства. Медиатекст соединяется с другими ресурсами как в самом издании, так и за его пределами, поэтому можно говорить о наличии в медиадискурсе также гипертекстовой и поликодовой связности. Комплексный анализ разных видов связности на материале двух языков составляет новизну проведенного исследования. Таким образом, современный медиадискурс - многоплановое и очень пестрое образование, выполняющее функцию не только информирования, но и постоянной, прочной и во многом глобальной и бесконечной связи между всеми сферами человеческой жизни.

Ключевые слова: медиадискурс, связность, гипертекстуальность, поликодовость, английский язык, немецкий язык.

Медиадискурс, понятие, на сегодняшний день определяемое как все множество текстов СМИ, средства их создания и условия существования, «совокупность созданных профессиональными журналистами текстов, функционирующих в ме-

(C) Санкт-Петербургский государственный университет, 2018 
диапространстве» [Желтухина 2007], тем не менее остается достаточно широким и предоставляет определенную свободу для новых исследований [Кожемякин 2010].

В данной статье рассматриваются виды связности в медиадискурсе, анализируется, с чем и как связан современный медиатекст, прослеживаются характер и глубина этих связей, а также взаимовлияние таких свойств медиадискурса, как связность, гипертекстуальность и поликодовость. Материалом исследования послужили 100 немецко- и англоязычных публицистических текстов из электронных версий изданий «The New York Times» и «Frankfurter Allgemeine Zeitung», которые на сегодняшний день считаются одними из самых авторитетных и читаемых СМИ по всему миру. Кроме того, в связи с выборами в США в ноябре 2016 г. представляется интересным проследить то, как такое знаковое событие отразилось в текстах, с одной стороны, американских изданий, а с другой - европейских, неанглоязычных. Внимание уделяется прежде всего сходству двух изданий в изучаемом аспекте.

В различных отечественных и зарубежных публикациях встречается множество характеристик медиадискурса, но в качестве важнейшего свойства всеми исследователями признается связность [Чернявская 2009; Милевская 2003; Коновалова 2015]. Ее основу формируют смысловые отношения в тексте, которые проявляются на двух уровнях: локальном и глобальном [Суховалова 2010]. В рамках данной статьи понятие «связность» трактуется обобщенно, в целом как способность медиатекстов обнаруживать не только лексико-грамматическую локальную связность на уровне предложений (когезия) [Rickheit, Schade 2000], но и более общую, смысловую, тематическую, или глобальную, связь (когерентность [Dijk 2013], или цельность) [Жучкова 2014]. В случае с электронными изданиями эта связь выходит за рамки отдельных текстов, рубрик или изданий и стремится далее, в бесконечное пространство сети Интернет [Лутовинова 2009]. При выходе на уровень дискурса обнаруживаются связи другого рода, основанные на таких свойствах современных СМИ, как поликодовость и гипертекстуальность [Storrer 2008]. Поликодовость - свойство, реализуемое при добавлении в текст фото или видео, т.е. в текстах современных СМИ, публикующихся в сети Интернет, представлены самые разные виды информации - текстовая, аудиальная, визуальная [Чернявская 2009]. Гипертекстуальность - это способ организации интернет-пространства, при котором огромное множество документов, или, шире, единиц информации, соединяются и образуют уже не линейную, а многомерную структуру медиадискурса [Соболева 2014]. В современном медиадискурсе, который в значительной степени существует в электронном виде, эти два свойства обусловлены наличием экстралингвистической связности медиатекстов, поэтому возможно различать поликодовые и гипертекстуальные виды связности отдельно. Комплексный анализ разных видов связности на материале двух языков составляет новизну проведенного исследования.

Локальная связность исследуемых текстов в медиадискурсе маркируется в языке на лексико-семантическом уровне, в частности в характере номинаций. В случае со знаковыми событиями цепочки одинаковых или схожих номинаций охватывают уже не только ряд статей, но также и целые издания и, выходя за рамки отдельных предложений или текстов, начинают формировать глобальную, тематическую связность в медиадискурсе. 
Удачным примером этому может служить феномен «трампизма», появившийся в СМИ в связи с прошедшими выборами в США, когда статьи всех рубрик и тематик так или иначе содержали упоминание нового лидера США. Например, передовица «The New York Times» содержала ссылки на следующие статьи:

(1) Vice President-Elect Tapped for Contacts in Washington

Vice President-elect Mike Pence will take over the job of leading Donald J. Trump's transition effort from Gov. Chris Christie [NYT 08.11.2016].

«Избранный вице-президент налаживает контакты в Вашингтоне

Избранный вице-президент Майк Пенс возглавит переход к правлению Дональда Дж. Трампа, сменив губернатора Криса Кристи» ${ }^{1}$;

(2) Trump Turns to His Right Flank to Fill National Security Posts

President-elect Donald J. Trump moved quickly on Friday to begin filling national security posts at the top echelons of his administration, selecting a group of hawks and campaign loyalists who reflect the hard-line views that defined his run for president [NYT 18.11.2016];

«Трамп обращается к правым, чтобы назначить на посты в национальной службе безопасности

В пятницу избранный президент Дональд Дж. Трамп начал быстро назначать на посты национальной службы безопасности в верхних эшелонах своей администрации, выбрав группу милитаристов и лоялистов, которые придерживаются того же жесткого курса, что был характерен для президентской кампании»;

(3) For Partners of Trump in India: 'President-Elect Branded' Bump

Developers who have built two Trump-branded towers in India met with Presidentelect Donald J. Trump last week, and one of them confirmed that they discussed future deals with the Trump family [NYT 20.11.2016].

«Партнерам Трампа в Индии: Бум по имени „Избранный президент“

Застройщики, воздвигшие два небоскреба для семьи Трампов в Индии, встретились с избранным президентом Дональдом Дж. Трампом на прошлой неделе, один из них подтвердил, что речь шла о будущих сделках с семьей Трамп».

На передовице каждая из этих ссылок представлена в виде заголовка-гиперссылки, подзаголовка, или первого абзаца статьи, а также дополнительно еще в виде одной-двух ссылок на статьи похожей тематики. Как видно из примеров, основные номинации связаны с фигурой нового президента США (leading Donald J. Trump, Trump, President-elect Donald J. Trump), и цепочки этих номинаций составляют основу повествования.

Упоминание Mr. Trump встречается среди других номинаций из области политики: Vice President-Elect, Gov. Chris Christie (пример 1), Right Flank, National Security Posts, hawks and campaign loyalists (пример 2), Trump University Settlement (пример 3), относящихся к различным сферам деятельности главного действующего лица повествования. Они создают цепочки номинаций, в которых прослеживаются основные факты новостного сообщения.

То же находим на страницах немецкого издания «Frankfurter Allgemeine Zeitung»:

${ }^{1}$ Здесь и далее перевод примеров на русский язык принадлежит автору статьи. 
(4) Wieder Proteste gegen Trump

Am dritten Tag in Folge gehen in mehreren amerikanischen Städten einige Tausend Menschen auf die Straße, um gegen Donald Trump zu protestieren. Für Sonntag ist eine große Demonstration in New York geplant [FAZ, 12.11.2016].

«Снова протесты против Трампа

Третий день подряд в нескольких американских городах тысячи людей выходят на улицы, чтобы протестовать против Дональда Трампа. На воскресенье запланирована большая демонстрация в Нью-Йорке»;

(5) Donald Trump ernennt Pence zum Teamleiter

Donald Trump trifft wichtige Personalentscheidungen. Erster Akt: Mike Pence übernimmt die Leitung des Übergangsteams. Sein Vorgänger ist ein zu großes Risiko für Trump [FAZ, 12.11.2016].

«Дональд Трамп назначает Пенса главой команды

Дональд Трамп принимает важные кадровые решения. Первое: Майк Пенс принимает руководство переходной командой. Его предшественник для Трампа слишком большой риск»;

(6) Ist Clinton doch die heimliche Präsidentin?

Hillary Clinton hat landesweit mehr Stimmen bekommen als Donald Trump. Müsste deswegen sie und nicht er Präsident werden? [FAZ, 11.11.2016].

«Клинтон все же тайный президент?

Хиллари Клинтон получила в целом по стране больше голосов, чем Дональд Трамп. Может, поэтому она, а не он, должна стать президентом?»

Имя собственное Trump используется как самостоятельно, так и включенным в другие номинации: Proteste gegen Trump (пример 4). При этом само имя не содержит в заголовках и подзаголовках никаких дополнительных компонентов, таких как характеристики через прилагательные, причастия и т. п., т.е. в самой номинации лица сохраняется нейтральная оценка главного персонажа. Некоторую долю оценки привносят такие номинации, как eine große Demonstration in New York (пример 4), Mike Pence, Teamleiter (пример 5), Hillary Clinton, die heimliche Präsidentin (пример 6). Они окружают номинацию Trump и связаны с реакцией на результаты выборов. Эти номинации также относятся к сфере политики и маркируют круг вопросов, обсуждаемых именно в той или иной статье, при этом общим остаются постоянные отсылки к имени нового президента.

Он упоминается также в статьях из разделов, посвященных другим темам, в частности медицине, бизнесу, культуре и др., - таким образом, присутствует глобальная связность многих рубрик и тем издания с основной актуальной темой. Например, это видно в заголовке и подзаголовке статьи о здравоохранении из «Тһе New York Times» (пример 7), а также в статье из рубрики «Business» («Бизнес») (пример 8):

(7) Trump Says He May Keep Parts of Obama Health Care Act

Mr. Trump indicated he would like to keep a provision that forces insurers to cover people with pre-existing conditions and another that allows parents to cover children into their mid-20s [NYT, 20.11.2016].

«Трамп утверждает, что может частично сохранить закон Обамы о здравоохранении 
Мистер Трамп сообщил, что хотел бы оставить в силе то положение, которое вынуждает страховщиков покрывать расходы людей с уже имеющимися заболеваниями, и то, которое позволяет родителям покрывать расходы детей до их 25-летия»;

(8) Businesses, Legal Fights and the Presidency

Mr. Trump's financial dealings and vast web of businesses pose a number of potential conflicts as he prepares to lead the country [NYT, 20.11.2016].

«Бизнес, правовые споры и президентство

Финансовые дела и обширная бизнес-сеть мистера Трампа могут спровоцировать ряд конфликтов в связи с его подготовкой к вступлению в должность президента».

Лингвистически связь маркируется в цепочках номинаций главного действующего лица (Trump), а также в номинациях, относящихся к лексико-семантическим полям данной рубрики. Так, в частности, для статьи из области медицины упоминается Health Care Act, insurers (пример 7), а для статьи о бизнесе Businesses, financial dealings, vast web of businesses (пример 8).

Упоминания нового президента присутствуют и в части статей, не связанных с политикой напрямую, например на тему современных технологий (пример 9) или спорта (пример 10):

(9) Technology

Daily Report: Online Media That Helped Make Trump

Partisan news sites that were clever with social media had a strong effect on the presidential campaign. What does that mean for the news business? [NYT, 08.11.2016].

«Технология

Ежедневный отчет: Онлайн-пресса, которая помогла становлению Трампа

Партийные новостные сайты, которые догадались сотрудничать с социальными СМИ, сильно повлияли на президентскую кампанию. Что это значит для новостного бизнеса?»;

(10) Sport

Emboldened N. B. A. Coaches Rip Donald J. Trump's Rhetoric

Gregg Popovich, Stan Van Gundy and Steve Kerr have openly criticized Mr. Trump since he won the presidential election [NYT, 08.11.2016].

«Спорт

Смелые тренеры НБА рвут риторику Дональда Дж. Трампа

Грегг Попович, Стэн Ван Ганди и Стив Керр открыто критикуют мистера Трампа с того момента, как он выиграл президентские выборы».

Номинации лица Trump, Donald J. Trump, Mr. Trump и президентской кампании the presidential campaign, the presidential election в соседстве с такими номинациями, как Online Media, Partisan news sites, social media, the news business (пример 9) или N. B. A. Gregg Popovich, Stan Van Gundy and Steve Kerr (пример 10), связывают темы, на первый взгляд не имеющие ничего общего.

В немецком издании «Frankfurter Allgemeine Zeitung» также встречается подобный удаленный характер связности: 
(11) Finanzen

Er hat nach Trumps Sieg Hunderte Millionen mit Aktien gewonnen

Viele Fachleute sagten starke Kurseinbrüche infolge einer Wahl Trumps voraus. Passiert ist das Gegenteil. Einer seiner Unterstützer verließ die Wahlparty, um groß einzusteigen [FAZ, 11.11.2016].

«Финансы

Он выиграл сотни миллионов на акциях после победы Трампа

Многие эксперты предсказывали сильные падения курсов после выборов Трампа. Но произошло противоположное. Один из его сторонников покинул вечеринку в честь выборов, чтобы разбогатеть»;

(12) Menschen

Mexikanerin in Amerika: „Mein Herz ist voller Angst“

Wie fühlt es sich an, jetzt als Mexikanerin in Trumps Amerika zu leben? Eine Mutter fürchtet den Tag, an dem ihr Sohn in den Kindergarten kommt. Hier spricht sie über ihre Ängste [FAZ, 11.11.2016].

«Люди

Мексиканка в Америке: „Мое сердце полно страха“

Как чувствуешь себя сейчас, если ты мексиканка и живешь в Америке при Трампе? Мать боится того дня, когда ее сын пойдет в детский сад. Она говорит здесь о своих страхах»;

(13) Feuilleton

Hillary Clintons Rhetorik: Wie gratuliert man Donald Trump?

Monatelang hieß es, Amerikas politische Kultur sei am Ende und mit Trump drohe der Weltuntergang. Warum also jetzt tapfer die rhetorische Form wahren, als sei alles nicht so gemeint gewesen? [FAZ, 11.11.2016].

«Фельетон

Риторика Хиллари Клинтон: Как поздравляют Дональда Трампа

На протяжении месяцев утверждалось, что политической культуре в Америке пришел конец и с Трампом им угрожает апокалипсис. Зачем даже сейчас смело придерживаться этого риторической формы, если речь шла о другом?»

В представленных трех примерах (11-13) видно, что номинация Trump сама по себе уже не встречается, вместо этого она все чаще включается в другие номинации, относящиеся, как и в англоязычном издании, к теме финансов, общества, культуры (в немецкоязычной рубрике «Feuilleton» («Фельетон»)). Если выстроить цепочку номинаций, видно, как автор постепенно уходит от собственно политической темы к другим новостям:

- пример 11: Trumps Sieg - Hunderte Millionen - Aktien - Wahl Trumps Kurseinbrüche - Einer seiner Unterstützer - Wahlparty;

- пример 12: Mexikanerin in Amerika - Herz... voller Angst - Mexikanerin in Trumps Amerika - Eine Mutter - ihr Sohn - Kindergarten - ihre Ängste;

- пример 13: Hillary Clintons Rhetorik - Donald Trump - Amerikas politische Kultur - Trump - Weltuntergang - die rhetorische Form.

В этом случае имя Трампа становится своеобразным толчком для освещения новых происшествий. Знаковое событие придает связности медиатекстов черты глобальности и бесконечности. 
В отношении гипертекстовых связей в анализируемых изданиях можно отметить, например, релевантные ссылки - переходы на другие статьи по теме. Так, в «The New York Times» правее основного текста статьи добавляется раздел «Related Coverage» («Еще по теме»), содержащий названия похожих по тематике статей. Для статьи, посвященной футболу, это следующие ссылки:

(14) Before U.S. and Mexico Play, Fans Push for Respect in a Charged Atmosphere [NYT, 11.11.2016]. «Перед игрой США против Мексики фанаты настаивают на взаимоуважении в накаленной обстановке»;

(15) 'It Is America. But I Want to Play in Mexico'. [NYT, 11.11.2016]. «Это Америка. Но я хочу играть в Мексике»;

(16) U.S. Is Hosting Mexico Again? Road Trip to Columbus! [NYT, 11.11.2016]. «США опять принимает Мексику? Путешествие в Колумбус!»

Такие статьи представлены только заголовками, но даже в небольшом текстовом фрагменте присутствуют номинации заданной тематики (Play, Fans). Имена собственные U.S. u Mexico употребляются как субъекты предложения в сочетании с глагольными формами play, is hosting, это позволяет идентифицировать такие имена собственные как названия футбольных клубов, а не как названия государств.

Статьи из «Frankfurter Allgemeine Zeitung» также содержат раздел «Mehr zum Thema» («Еще по теме») или «Weitere Empfehlungen» («Рекомендуем также»), включающий перечень других статей похожей тематики. Так, в конце статьи, посвященной новому роману о беженцах, можно встретить следующие ссылки:

(17) CSU-Politiker warnt

Familiennachzug größeres Problem als neue Flüchtlinge [FAZ, 29.12.2016].

«Политик Христианско-социального союза предупреждает

Воссоединение семей - проблема серьезнее, чем новые беженцы»;

(18) Berlin-Attentäter

Amri bekannte sich per Video zum IS [FAZ, 29.12.2016].

«Берлинские террористы

Амри делает признание в видео Исламского государства»;

(19) Oguz Atys Roman Die Haltlosen

Was habe ich in dieser Wohnung noch verloren? [FAZ, 29.12.2016].

«Роман Огуза Атиса „Беспринципные“

Что еще я оставил в этой квартире?»

Интересно отметить, что аналогичные элементы различаются по структуре в англо- и немецкоязычном издании. В «The New York Times» ссылка представляет собой только название релевантной статьи и дату ее выхода, в то время как во «Frankfurter Allgemeine Zeitung» печатается название раздела (CSU-Politiker warnt, Berlin-Attentäter, Oguz Atys Roman Die Haltlosen), далее название статьи, а также включаются подзаголовок, дата выхода и иногда имя автора. Кроме того, релевантность таких статей относительна: новые ссылки содержат номинации из области политики (CSU-Politiker) или общества (Flüchtlinge, Berlin-Attentäter), а не только из области культуры (Oguz Atys Roman). 
Среди дополнительных сведений, отображающихся в статье, могут присутствовать как релевантные блоки, описанные выше, так и менее релевантные. Например, анализируемые издания предлагают подписку на новости (пример 20) или более подробное знакомство с изданием (пример 21):

(20) Sign Up for the Sports Newsletter

Get the big sports news, highlights and analysis from Times journalists, with distinctive takes on games and some behind-the-scenes surprises, delivered to your inbox every week [NYT, 12.11.2016].

«Подписывайтесь на спортивные новости

Узнавайте главные новости спорта, тренды и комментарии журналистов „Таймс“, всё об играх и закадровых сюрпризах, каждую неделю по электронной почте»;

(21) Nichts mehr verpassen

Frankfurter Allgemeine Stil auf Facebook [FAZ, 29.12.2016].

«Больше ничего не пропускать

Стиль Франкфуртер Альгемайне на „Фейсбук“».

Кроме того, статьи часто содержат ссылки на видео-, аудио- и фотофрагменты. В этом случае в медиатексте проявляются поликодовые связи путем включения релевантных фрагментов аудио-, фото- и видеорядов по теме сообщения, а также и нерелевантных блоков рекламы, которая не относится непосредственно к обсуждаемому в статье. Например, в разделе «From Our Advertisers» («От наших рекламодателей») даются реклама изумрудов в статье о футболе (пример 22) или реклама Федерального министерства по труду и социальным вопросам Германии в статье о стиле жизни (пример 23):

(22) MUZO Curious about Emeralds? Find out more about Colombia's gem-cutting tradition [NYT 12.11.2016].

«МУЗО Интересуют изумруды? Узнайте больше о колумбийских традициях огранки»;

(23) Mehr möglich machen. Weniger behindern [FAZ 01.12.2016].

«Сделать возможным больше. Меньше мешать».

Имеются также широчайшие возможности коммуникации и практически мгновенной реакции на события, их немедленного обсуждения в социальных сетях. Каждая статья «The New York Times» и «Frankfurter Allgemeine Zeitung» независимо от тематики имеет иконки-ссылки на «Facebook», «Instagram», а также ссылки, позволяющие отправить статью по электронной почте или распечатать:

(24) Share Tweet Email More Save [NYT, 29.12.2016]. «Поделиться Твитнуть Отправить по электронной почте Еще Сохранить»;

(25) Teilen Twittern E-mailen Merken Empfehlen [FAZ, 29.12.2016]. «Поделиться Твитнуть Отправить по электронной почте Отметить Рекомендовать».

Эти возможности вообще не относятся к основной теме сообщения, т.е. нерелевантны по сути, однако же очень актуальны в эпоху онлайн-общения и также формируют практически бесконечные связи в медиадискурсном пространстве. 
Подводя итог, можно отметить, что локальная связность в медиадискурсе, выражаемая номинациями, относящимися к теме сообщения, становится основой для глобальной связности, когда знаковые события проникают во многие сферы жизни общества. Лингвистически это находит отражение в постоянном повторении номинаций, связанных с главным событием, на протяжении нескольких статей, в разных изданиях и в статьях на самые разные темы.

Медиатексты также обнаруживают связность экстралингвистического характера. Она проявляется в наличии релевантных ссылок на новостные сообщения, а также нерелевантных ссылок на рекламу и социальные сети, которые позволяют делиться новостью и обсуждать ее с другими участниками веб-пространства. Медиатекст соединяется с другими ресурсами как в самом издании, так и за его пределами, поэтому можно говорить о наличии в медиадискурсе также гипертекстовой и поликодовой связности.

Таким образом, современный медиадискурс - многоплановое и очень пестрое образование, выполняющее не только функцию информирования, но и постоянной, прочной и во многом глобальной и бесконечной связи между всеми сферами человеческой жизни. В этом случае собственно лингвистический компонент, хотя и остается фундаментальным условием связности, но уже не является ее единственным маркером. Медиадискурс выходит за рамки собственно языкового явления и включает в себя элементы более широкого порядка.

\section{Источники}

FAZ - Frankfurter Allgemeine [Zeitung]. URL: http://www.faz.net/ (даты обращения: 11.11.2016, 12.11.2016, 01.12.2016, 29.12.2016).

NYT - The New York Times. URL: https://www.nytimes.com/ (даты обращения: 08.11.2016, 11.11.2016, 18.11.2016, 20.11.2016, 29.12.2016).

\section{Литература}

Желтухина 2007 - Желтухина М.Р. “О содержании дискурса масс-медиа”. Вісник Луганського пед. ун-ту ім. Т. Шевченка. Серія «Філологічні науки». 11 (128), ч. 1, 2007: 27-40.

Жучкова 2014 - Жучкова И.И. “О сущности и специфике использования терминов «соhesion» (связность) и «соherence» (цельность) в англоязычном и русском языкознании”. Вектор науки Тольяттинского гос. ун-та. 3 (29), 2014: 155-159.

Кожемякин 2010 - Кожемякин Е.А. "Массовая коммуникация и медиадискурс: К методологии исследования”. Научные ведомости Белгородского гос. ун-та. Серия «Гуманитарные науки». 6 (12), 2010: 13-21.

Коновалова 2015 - Коновалова М. В. “Медиадискурс и подходы к его изучению”. Вестник Челябинского гос. ун-та: Филологические науки. 27 (382), 2015: 101-108.

Лутовинова 2009 - Лутовинова О.В. Лингвокультурологические характеристики виртуального дискурса. Волгоград: Перемена, 2009, 476 с.

Милевская 2003 - Милевская Т. В. Связность как категория дискурса и текста (когнитивно-функциональный и коммуникативно-прагматический аспекты). Ростов н/Д.: Ростовский гос. пед. ун-т, 2003, 386 с.

Соболева 2014 - Соболева О. В. “К проблеме определения понятия «гипертекстуальность»”. Вестник Челябинского гос. ун-та: Филология. Искусствоведение. 7 (336), 2014: 72-75.

Суховалова 2010 - Суховалова Е.А. "Категории когезии и когерентности в контексте англоязычного политического дискурса”. Вестник Московского гос. тингвистич. ун-та: Языкознание. 8 (587), 2010: 40-49. 
Чернявская 2009 - Чернявская В. Е. Лингвистика текста: Поликодовость, интертекстуальность, интердискурсивность: учеб. пособие. М.: Либро-Ком, 2009, 284 с.

Dijk 2013 - Dijk T. A. van. News as Discourse. S. 1.: Routledge, 2013, 208 p.

Rickheit, Schade 2000 - Rickheit G., Schade U. "Kohärenz und Kohäsion”. Text- und Gesprächslinguistik: Ein internationales Handbuch zeitgenössischer Forschung. Brinker K. et al. (Hrsg.). Vol. 1. Berlin; New York: Walter de Gruyter, 2000, SS. 275-283.

Storrer 2008 - Storrer A. "Hypertextlinguistik". Textlinguistik: 15 Einführungen. Janich N. (Hrsg.). Tübingen: Gunter Narr, 2008, SS. 315-332. (Narr Studienbücher).

Статья поступила в редакцию 8 января 2017 г. Статья рекомендована в печать 14 апреля 2017 г.

\section{Solntseva Elena Sergeevna}

St. Petersburg State University, 11, Universitetskaya emb., St. Petersburg, 199034, Russia; shelestelena@yandex.ru

\section{Types of coherence in media discourse}

For citation: Solntseva E.S. Types of coherence in media discourse. Vestnik of Saint Petersburg University. Language and Literature, 2018, vol. 15, issue 3, pp. 481-491. https://doi.org/10.21638/ spbu09.2018.312 (In Russian)

The article touches upon the types of coherence in media discourse that mean how modern media texts are connected with each other. The main attention is paid to the correlation between coherence, hypertextuality and multimodality. The examples are taken from 100 articles of English and German online issues, "The New York Times" and "Frankfurter Allgemeine Zeitung", as they are among the most reputable and popular mass media around the world. Moreover, regarding the elections in the USA in 2016 it becomes of interest to follow how this remarkable event found its reflection in American texts, on the one hand, and in the European non-English ones, on the other. The coherence between the media texts is provided mainly by four types of coherence, such as local, global, hypertextual and multimodal coherence. Local coherence is based on the consistency of subject and naming units, in this case the naming units of the most important event become the base of the text and create the correlation between media texts of different subjects and different issues, turning the local coherence into the global one. Furthermore, the media texts are connected by extralinguistic means, the hyperlinks and multimodal elements in particular. The hyperlinks and the multimodal structure in a modern media text form the coherence of media with other network resources. These can be relevant links to other news articles or irrelevant ones to adverts or social networks providing greater possibilities to discuss an event within the online space. The new and original approach presented in the article is in the integrated analysis of different types of coherence in mass media on examples taken from two languages. Regarding this we deal with media discourse as a widespread, multistructural and infinite phenomenon establishing solid global coherence between all spheres of people's life.

Keywords: media discourse, coherence, hypertextuality, multimodal text, English, German.

\section{Sources}

FAZ - Frankfurter Allgemeine [Zeitung]. URL: http://www.faz.net/ (accessed dates: 11.11.2016, 12.11.2016, 01.12.2016, 29.12.2016).

NYT - The New York Times. URL: https://www.nytimes.com/ (accessed dates: 08.11.2016, 11.11.2016, 18.11.2016, 20.11.2016, 29.12.2016). 


\section{References}

Желтухина 2007 - Zheltukhina M.R. "O soderzhanii diskursa mass-media [On the Content of the Discourse of the Media]”. Visnik Lugans'kogo ped. un-tu im. T. Shevchenka [Bulletin of Lugansk Pedagogical University named after T. Shevchenko]. Seriia «Filologichni nauki» [Series "Philological Sciences"]. 11 (128), part 1, 2007: 27-40. (In Russian)

Жучкова 2014 - Zhuchkova I. I. "O sushchnosti i spetsifike ispol'zovaniia terminov «cohesion» (sviaznost') $\mathrm{i}$ "coherence» (tsel'nost') v angloiazychnom i russkom iazykoznanii [On the Implications and Characteristic Aspects of the Terms "Cohesion" and "Coherence" in the English and Russian Linguistics]". Vektor nauki Tol'iattinskogo gos. un-ta [Science Vektor of Togliatti State University]. 3 (29), 2014: 155159. (In Russian)

Кожемякин 2010 - Kozhemiakin E. A. "Massovaia kommunikatsiia i mediadiskurs: K metodologii issledovaniia [Mass Communication and Media Discourse: To the Methodology of Research]". Nauchnye vedomosti Belgorodskogo gos. un-ta [Bulletin of Belgorod State University]. Seriia "Gumanitarnye nauki» [Series "Scientific. Humanities"]. 6 (12), 2010: 13-21. (In Russian)

Коновалова 2015 - Konovalova M. V. "Mediadiskurs i podkhody k ego izucheniiu [Media Discourse and Approaches to Its Study]". Vestnik Cheliabinskogo gos. un-ta: Filologicheskie nauki [Bulletin of Chelyabinsk State University: Philology Sciences]. 27 (382), 2015: 101-108. (In Russian)

Лутовинова 2009 - Lutovinova O. V. Lingvokul'turologicheskie kharakteristiki virtual'nogo diskursa [Linguistic and Cultural Characteristics of Virtual Discourse]. Volgograd: Peremena Publ., 2009, 476 p. (In Russian)

Милевская 2003 - Milevskaia T.V. Sviaznost' kak kategoriia diskursa i teksta (kognitivno-funktsional'nyi i kommunikativno-pragmaticheskii aspekty) [Coherence as a Category of Discourse and Text (Cognitive-functional and Communicative-pragmatic Aspects)]. Rostov-on-Don: Rostov State Pedagogical University Press, 2003, 386 p. (In Russian)

Соболева 2014 - Soboleva O. V. “K probleme opredeleniia poniatiia "gipertekstual'nost'» [Towards Defining the Concept of "Hhypertextuality"]". Vestnik Cheliabinskogo gos. un-ta: Filologiia. Iskusstvovedenie [Bulletin of Chelyabinsk State University: Philology. Art Theory]. 7 (336), 2014: 72-75. (In Russian)

Суховалова 2010 - Sukhovalova E. A. "Kategorii kogezii i kogerentnosti v kontekste angloiazychnogo politicheskogo diskursa [Categories of Cohesion and Coherence in the Context of English-language Political Discourse]". Vestnik Moskovskogo gos. lingvistich. un-ta: Iazykoznanie [Bulletin of Moscow State Linguistic University: Humanities. 8 (587), 2010: 40-49. (In Russian)

Чернявская 2009 - Cherniavskaia V.E. Lingvistika teksta: Polikodovost', intertekstual'nost', interdiskursivnost' [Linguistics of the Text: Polycodicity, Intertextuality, Interdiscursivity]. Moscow: Libro-Kom Publ., 2009, 284 p. (In Russian)

Dijk 2013 - Dijk T. A. van. News as Discourse. [S.1.]: Routledge, 2013, 208 p. (In English)

Rickheit, Schade 2000 - Rickheit G., Schade U. "Kohärenz und Kohäsion”. Text- und Gesprächslinguistik: Ein internationales Handbuch zeitgenössischer Forschung. Brinker K. et al. (Hrsg.). Vol. 1. Berlin; New York: Walter de Gruyter, 2000, SS. 275-283.

Storrer 2008 - Storrer A. "Hypertextlinguistik". Textlinguistik: 15 Einführungen. Janich N. (Hrsg.). Tübingen: Gunter Narr, 2008, SS. 315-332. (Narr Studienbücher). 